\title{
Systematic review of mini-implant displacement under orthodontic loading
}

\author{
Manuel Nienkemper ${ }^{1}$, Jörg Handschel ${ }^{2}$ and Dieter Drescher ${ }^{1}$
}

A growing number of studies have reported that mini-implants do not remain in exactly the same position during treatment, although they remain stable. The aim of this review was to collect data regarding primary displacement immediately straight after loading and secondary displacement over time. A systematic review was performed to investigate primary and secondary displacement. The amount and type of displacement were recorded. A total of $\mathbf{2 7}$ studies were included. Sixteen in vitro studies or studies using finite element analysis addressed primary displacement, and nine clinical studies and two animal studies addressed secondary displacement. Significant primary displacement was detected $(6.4-24.4 \mu \mathrm{m})$ for relevant orthodontic forces $(0.5-2.5 \mathrm{~N})$. The mean secondary displacement ranged from 0 to $2.7 \mathrm{~mm}$ for entire mini-implants. The maximum values for each clinical study ranged from 1.0 to $4.1 \mathrm{~mm}$ for the head, 1.0 to 1.5 for the body and 1.0 to $1.92 \mathrm{~mm}$ for the tail part. The most frequent type of movement was controlled tipping or bodily movement. Primary displacement did not reach a clinically significant level. However, clinicians can expect relevant secondary displacement in the direction of force. Consequently, decentralized insertion within the inter-radicular space, away from force direction, might be favourable. More evidence is needed to provide quantitative recommendations. International Journal of Oral Science (2013) 6, 1-6; doi:10.1038/ijos.2013.92; published 20 December 2013

Keywords: displacement; migration; mini-implant; miniscrew; orthodontics; skeletal anchorage

\section{INTRODUCTION}

To withstand the reactive forces that occurred during tooth movement and prevent negative side effects, a stable anchorage unit is necessary. ${ }^{1-2}$ New solutions to provide sufficient anchorage have become feasible with the use of skeletal anchorage. ${ }^{3-6}$ In the last few years, miniimplants in particular have become increasingly popular for anchorage reinforcement. $^{7-9}$ Mini-implants have proved to provide reliable anchorage in various clinical situations. ${ }^{10-11}$ Their versatility has made new types of mechanics and treatment options possible. ${ }^{12-13}$ Regarding orthodontic mini-implants, current meta-analyses have reported a success rate of $83.6 \% .^{14-15}$

A basic requirement for success is sufficient primary stability. ${ }^{16}$ Different factors affecting primary stability have been reported in the literature:

First, a region with high bone quality should be chosen. ${ }^{17}$ The bone should be covered with a thin, attached mucosa to allow for sufficient insertion depth. ${ }^{18}$ Additionally, different aspects concerning insertion protocol should be considered. ${ }^{18-20}$ Regarding the implant design, increased diameter $^{21-22}$ and length ${ }^{23-24}$ have resulted in longer survival rates and greater stability. ${ }^{25}$ In these studies, success rate has been defined as 'survival rate' or 'remaining stable'.

Being integrated into the surrounding bone, endosseous implants remain absolutely stationary when orthodontic force is applied. ${ }^{26-27}$ Correspondingly, mini-implants are also often considered to offer absolute anchorage. This assumption applies that they do not move in the direction of force and therefore prevent movement of the anchorage unit. ${ }^{28-29}$

However, Liou et al. ${ }^{30}$ suggested that orthodontic mini-implants did not remain in their positions under orthodontic loading although they remained stable. Regarding mini-implant displacement, it can be differentiated between direct, primary displacement, due to elastic characteristics of the bone and periodontal structures and migration or secondary displacement under loading over the treatment time caused by remodelling processes. These phenomena can cause clinical problems:

The alveolar ridge is the most common insertion site for orthodontic mini-implants. ${ }^{14-15}$ Root contact and close proximity to the roots are well-known risk factors for mini-implant failure. ${ }^{31-32}$ Direct root contact or even a proximity of less than $0.6 \mathrm{~mm}$ between the miniimplant and root surface can also cause root resorption. ${ }^{33-34}$ These complications may also occur when mini-implants are displaced during treatment.

The question that arises is whether orthodontic mini-implants are really displaced by orthodontic force. What are the dimensions of primary displacement, due to elastic characteristics of the implant supporting structures, and of secondary displacement, caused by bone remodelling under loading? Which of the aforementioned factors regarding primary stability can affect mini-implant displacement? Are there new suggestions regarding the required space for insertion?

To answer these questions, a systematic review was performed. 


\section{MATERIALS AND METHODS}

A search was performed using PubMed and Scopus up to the end of July 2013. The aim was to identify all papers dealing with orthodontic miniimplants and primary and/or secondary displacement. Primary or direct displacement was defined as follows: immediate displacement of a miniimplant loaded with force due to the elastic and plastic properties of the bone. Secondary displacement, i.e., migration was defined as follows: long-term displacement of a mini-implant loaded with force due to the remodelling processes of the bone. The search strategy is shown in Figure 1.

From the articles found using the keyword search, those articles meeting the inclusion criteria were included. One additional study was found by hand searching.

The inclusion criteria were

- published in either the German or English language;

- measurement of mini-implant displacement;

- a clear description of study design; and

- reproducible measuring methods.

All of the articles were selected independently by each author regarding their content. Only studies quantifying displacement were included. These papers were divided into articles dealing with primary displacement and those dealing with secondary displacement.

In the primary displacement group, in vitro studies using both human jaws and animal bone were included. Additionally, studies using finite element analysis for the simulation of primary displacement were evaluated and compared with the in vitro results.

In addition to the range of displacement, the insertion site, size and design of the mini-implants were considered.

In the secondary displacement group, only clinical and animal studies were included. Regarding clinical trials, prospective, as well as retrospective, studies were selected, whereas case reports and review articles were excluded.

Clinical and animal studies were judged according to their study designs. Data were collected regarding the accuracy of the measurement method, adequacy of the method error analysis, statistical analysis and sample size.
For the analysis of secondary displacement, the mean and maximum horizontal and vertical displacements were measured. Whenever possible, the type of mini-implant movement was assessed.

Insertion site and technique, as well as the size and design of the mini-implants, were considered. Articles were also evaluated regarding healing period, level of force, loading time and rate of miniimplant failure. Concerning orthodontic treatment, anchorage modes and indications for skeletal anchorage were recorded.

\section{RESULTS}

The systematic search by keywords resulted in 68 hits (Figure 1). A total of 63 articles were published in English or German. Application of the inclusion and exclusion criteria led to 26 relevant articles. One additional clinical study was identified by hand searching, so a total of 27 articles were included.

Sixteen papers were found dealing with primary displacement; these papers included in vitro studies with different types of bone $(n=9)$ and studies using finite element analysis for the simulation of mini-implants in bone $(n=7)$. The 11 articles regarding secondary displacement were divided into clinical studies $(n=9)$ and animal studies $(n=2)$.

\section{Primary displacement}

In vitro studies ${ }^{35-36}$ reported a primary displacement of less than $0.5 \mathrm{~mm}$ using forces of up to $20 \mathrm{~N}$ (Table 1). Akyalcin et al. ${ }^{37}$ reported of force levels of 56-98 $\mathrm{N}$ to achieve a displacement of $1 \mathrm{~mm}$. Focusing on forces relevant for orthodontic treatment $(0.5-2.5 \mathrm{~N})$, displacement ranged from 6.4 to $24.4 \mu \mathrm{m} .{ }^{38-43}$ Holst et al. ${ }^{39}$ observed significant displacement beyond elastic recovery of the surrounding bone. Consistently, Pittman et $a l^{43}$ reported residual displacement after $2 \mathrm{~h}$ of loading after being unloaded again. Bicortical placement reduced displacement. ${ }^{36}$ Within the results of in vitro studies, different insertion angles did not affect the level of deflection. ${ }^{38}$ Regarding mini-implant design, Su et al. ${ }^{40}$ found no differences between self-tapping and self-drilling screws. Size and shape seemed to play roles in general, with less displacement for larger and conical designs. ${ }^{39}$ In contrast, Chatzigianni et al. observed no differences regarding size for low forces $(<0.5 \mathrm{~N})$. These authors also compared

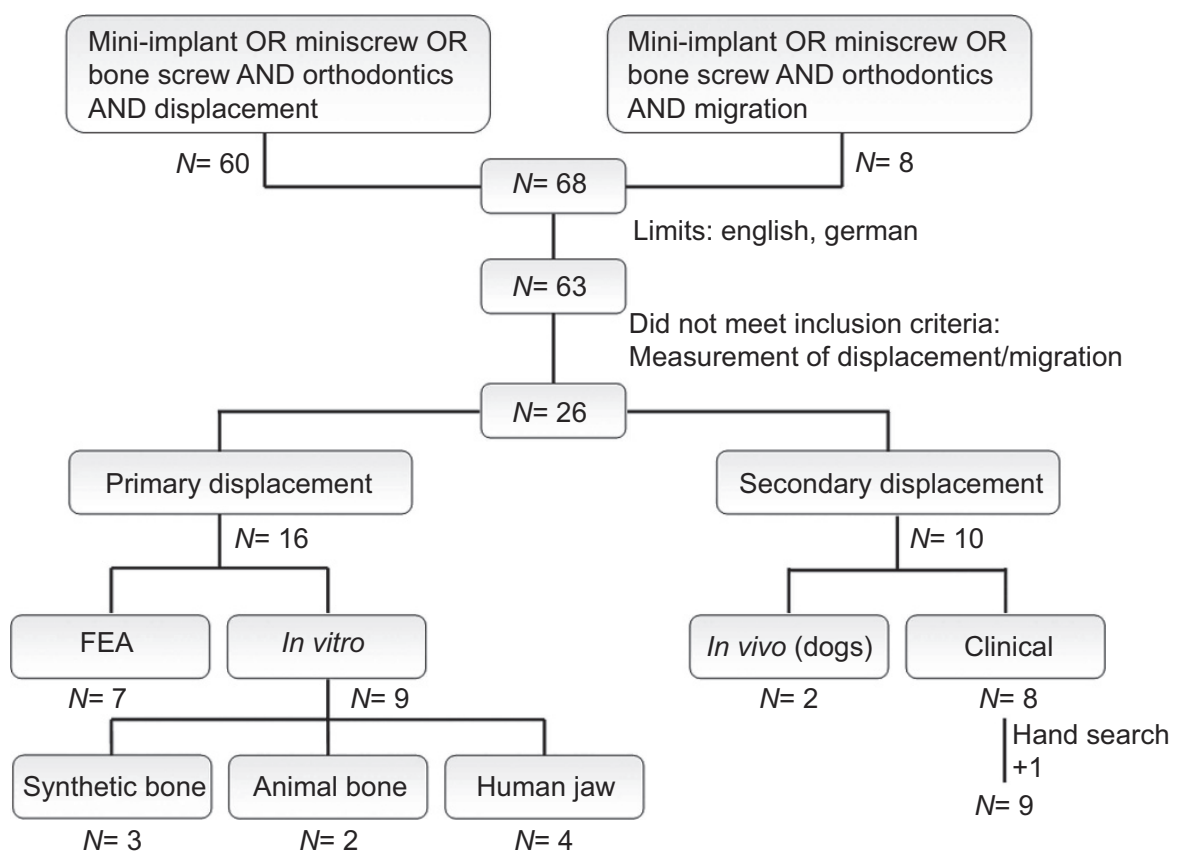

Figure 1 Search strategy and results. $N$, number of studies found. 
Table 1 Results of the in vitro and finite element studies regarding primary displacement

\begin{tabular}{|c|c|c|c|c|c|c|}
\hline Studies & Bone & Insertion region & $n$ & Implant size/ $(\mathrm{mm} \times \mathrm{mm})$ & Force/N & Primary displacement/mm \\
\hline \multicolumn{7}{|l|}{ In vitro } \\
\hline Holst et al. 2010 & Human & Alveolar ridge; maxilla & 39 & $\mathrm{n} / \mathrm{a}$ & 2.5 & $0.02-0.25$ \\
\hline Morarend et al. 2009 & Human & $\begin{array}{l}\text { Alveolar ridge; } \\
\text { maxilla+mandible }\end{array}$ & 96 & $2.5 \times 17 ; 1.5 \times 15$ & 10 & $<0.3$ \\
\hline Brettin et al. 2008 & Human & $\begin{array}{l}\text { Alveolar ridge; } \\
\text { maxilla+mandible }\end{array}$ & 44 & $1.5 \times 15$ & 20 & $<0.5$ \\
\hline Pittman et al. 2013 & Human & Basal part; mandible & 26 & $1.5 \times 6$ & 0-2 & $<0.025$ \\
\hline Hong et al. 2010 & Biosynthetic bone & & 20 & $1.5 \times 6$ & $>2$ & 0.01 \\
\hline Hong et al. 2011 & Biosynthetic bone & & 100 & $1.3 \times 5.5 ; 1.9 \times 6.1$ & $>2$ & 0.02 \\
\hline Akyalcin et al. 2013 & Biosynthetic bone & & 120 & $1.4 \times 8 ; 1.5 \times 8$ & $1.1-98.5$ & $0.025-1.0$ \\
\hline \multicolumn{7}{|l|}{ Finite element } \\
\hline Jang et al. 2011 & & & & $1.6 \times 7$ & 2 & $0.00087-0.00100$ \\
\hline Motoyoshi et al. 2005 & & & & $1.4 \times 4$ & 2 & $0.000173-0.000185$ \\
\hline
\end{tabular}

n/a, data was not available.

between in vitro and finite element analysis (FEA) studies. Their results indicated that FEA was feasible for the simulation of an in vitro situation.

Using FEA, most of the authors reported little displacement ranging from 0.173 to $0.919 \mu \mathrm{m} .^{44-47}$ Only Chang et al. observed displacement of up to $0.315 \mathrm{~mm}$, although the level of force was comparable. ${ }^{48}$ Comparing the results of different studies, the use of larger mini-implants did not seem to result in less displacement. However, within the same finite element model, size significantly affected the level of displacement, although a comparison of quantitative data between different finite element models could not be performed. ${ }^{47}$ There was no effect of modifying the thread pitch, ${ }^{45}$ whereas greater depth of the threads resulted in greater displacement. ${ }^{48}$ Liu et al. ${ }^{47}$ noted that the ratio between the inserted and external parts of the mini-implant was one of the most important factors affecting displacement. In contrast to the results of in vitro studies, insertion angle affected lateral displacement in a FEA study. ${ }^{49}$

\section{Secondary displacement}

The study design of the selected, mostly uncontrolled clinical trials appeared appropriate (Table 2). All of the studies used image-based radiographic techniques, with superimposition of pre- and post-treatment data, for the evaluation of mini-implant displacement. Superimposition was performed by means of stable structures. Three three-dimensional techniques were chosen. Five investigations were based on lateral cephalograms. Only one study used occlusal Xrays. Method error, according to Dahlberg, ${ }^{50}$ was performed in four studies. The statistical analysis was adequate.

In all of the clinical studies, the mini-implants were loaded with horizontal force and comparable force levels ranging from 1.5 to $2.5 \mathrm{~N}$ (Table 3). Except for one study, in all of the studies, a direct anchorage mode was used. The loading period ranged from 5 to 8.5 months. The healing period ranged from 0 to 28 days; whereas most authors waited

Table 2 Study designs of clinical trials

\begin{tabular}{|c|c|c|c|c|c|c|c|}
\hline Studies & Study design & Type of study & $\begin{array}{l}\text { Sample size } \\
\text { calculation }\end{array}$ & Measuring method & Method error & Special analysis & Statistics \\
\hline \multicolumn{8}{|l|}{ Clinical } \\
\hline Liou et al. 2004 & CT & Retrospective & No & Superimposition; cephalogramms & Yes & - & Adequate \\
\hline El-Beialy et al. 2009 & CT & Prospective & No & Superimposition; dental CT & No & $\begin{array}{l}\text { Measured twice after } 2 \\
\text { weeks }\end{array}$ & Adequate \\
\hline Liu et al. 2011 & CT & Retrospective & No & Superimposition; dental CT & Yes & $\begin{array}{l}\text { Point registration three } \\
\text { times; measured } \\
\text { twice; mean }\end{array}$ & Adequate \\
\hline Alves et al. 2011 & CT & Prospective & No & Superimposition; CBCT & No & Measured twice; mean & Adequate \\
\hline Wang et al. 2006 & CT & Retrospective & No & Superimposition; cephalogramms & Yes & - & Adequate \\
\hline Hedayati et al. 2007 & RCT & Prospective & No & Superimposition; cephalogramms & No & Measured twice; mean & Adequate \\
\hline Calderon et al. 2011 & CT & Prospective & No & Superimposition; occlusal X-ray & No & $\begin{array}{l}\text { Cone beam CT for } \\
\text { calibration }\end{array}$ & Inadequate \\
\hline Lifshits et al. 2010 & CT & Prospective & No & Superimposition; cephalogramms & Yes & - & Adequate \\
\hline Kinzinger et al. 2008 & CT & Retrospective & No & Superimposition; cephalogramms & No & Measured twice; mean & Adequate \\
\hline \multicolumn{8}{|l|}{ Animal } \\
\hline $\begin{array}{l}\text { Mortensen et al. } \\
2009\end{array}$ & CT & Prospective & No & $\begin{array}{l}\text { Clinical measurement with digital } \\
\text { calliper }\end{array}$ & No & $\begin{array}{l}\text { Repeated } \\
\text { measurements }\end{array}$ & Adequate \\
\hline Ohmae et al. 2001 & $\mathrm{CT}$ & Prospective & No & $\begin{array}{l}\text { Superimposition of dental } \\
\text { radiographs }\end{array}$ & No & - & Descriptive \\
\hline
\end{tabular}

$\mathrm{CT}$, clinial trial (without control group); RCT, randomized controlled clinical trial. 


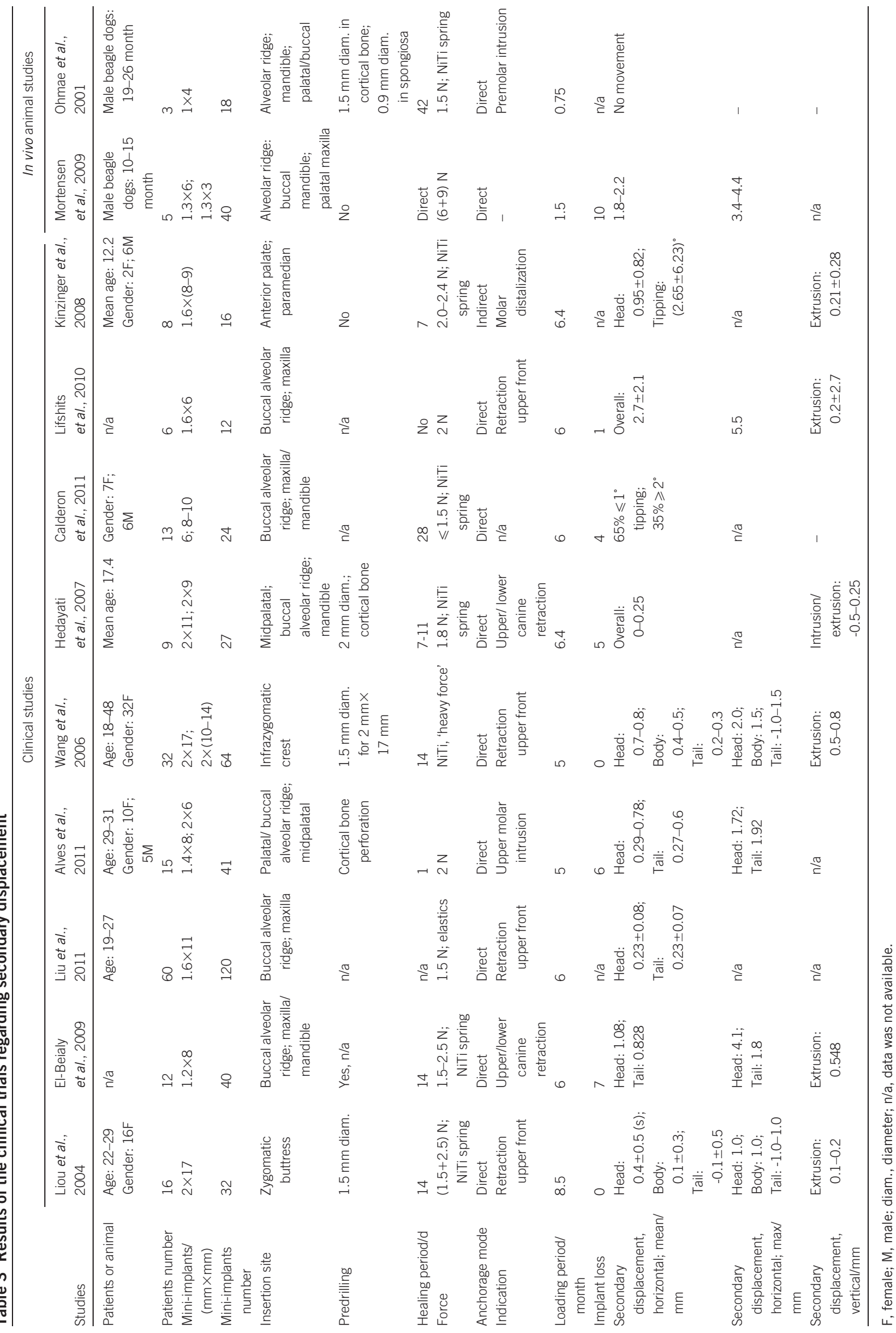


7-14 days until loading. The mean secondary displacement of the entire mini-implants ranged from 0 to $2.7 \mathrm{~mm}$ with maximum values of up to $5.5 \mathrm{~mm} .{ }^{51-52}$ Studies differentiating the movement of the mini-implants' parts observed mean displacements of $0.23-1.08 \mathrm{~mm}$ for the head part, $0.1-0.5$ for the body and $0.1-0.828 \mathrm{~mm}$ for the tail. The maximum values ranged from 1.0 to $4.1 \mathrm{~mm}$ for the head, 1.0 to 1.5 for the body and 1.0 to $1.92 \mathrm{~mm}$ for the tail part. Two studies also investigated a tipping angle ranging from 1.0 to $2.65^{\circ .53-54}$ The mean extrusion of the mini-implants ranged from 0.1 to $0.8 \mathrm{~mm}$, with only one author reporting intrusion of up to $0.5 \mathrm{~mm}$.

The two animal studies were performed using mature male beagle dogs. The first study confirmed that secondary displacement occurred. ${ }^{55}$ Using small screws loaded with high forces up to $9.0 \mathrm{~N}$, the mean movement was $2.2 \mathrm{~mm}$ within 6 weeks. In the second study, no movement beyond measurement inaccuracy was observed using superimposition of dental X-rays. ${ }^{56}$

\section{DISCUSSION}

Regarding primary displacement, the studies evaluated whether there was significant movement immediately after loading, even beyond elastic recovery of the surrounding bone. ${ }^{39,43}$ With movement dimensions of less that $0.1 \mathrm{~mm}$ in most of the studies, no direct clinical consequences of primary displacement could be observed. ${ }^{38-42}$ However, the factors possibly affecting primary displacement might be fundamental for further research regarding secondary displacement. Aspects such as corpus ${ }^{39}$ or thread design, ${ }^{57}$ which seem play important roles in this regard, might be interesting starting points for future investigations.

Clinical studies have varied in many factors, such as implant dimension, insertion protocol, insertion site or types of patients, making it very difficult to compare the influence of one parameter regarding secondary displacement between studies. Within the studies, only one or two parameters were used as variables.

The current results of clinical investigations suggest that the size of the mini-implant and the insertion site play important roles. ${ }^{53}$ The most important factor seems to be loading duration, whereas the amount of force seems to be less important, as long as it does not exceed normal orthodontic levels. ${ }^{58}$ Moreover, there was no significant difference between self-tapping and self-drilling mini-implants. ${ }^{58}$

Liu reported that movement of stable mini-implants could not be explained by a periodontal pressure-tension concept. ${ }^{59}$ He discussed the mechanostat theory of Frost, ${ }^{60-61}$ which is based on peak strain of dynamic loading controlling the remodelling processes. Therefore, he recommended finite element analysis to evaluate the stress and strain distributions in the surrounding bone. Nevertheless, the exact mechanism remains ambiguous. In this context, further investigations regarding the influence of different healing periods would be desirable. Liou et al. ${ }^{30}$ discussed whether a healing period of 2 weeks was too short to obtain sufficient osseointegration. Perhaps a treatment of the mini-implants' surface might affect the process of osseointegration and therefore the displacement behaviour, as suggested by Calderon et al..$^{53}$

However, all authors have affirmed that mini-implants provide good anchorage quality regarding orthodontic treatment. Nevertheless, all of the studies except one confirmed that significant secondary displacement occurred. The level of displacement is clinically relevant regarding interference with anatomical structures. The mean values for the displacement of the whole mini-implant ranged from a mean displacement of 0 to $2.7 \mathrm{~mm} .{ }^{51-52}$ However, in every study that quoted the maximum displacement, the values were at least $1.0 \mathrm{~mm}$ ranging up to
$5.5 \mathrm{~mm}^{30,51,58,62-63}$ Therefore, the clinician must expect significant displacement.

Regarding the type of movement Wang et al. ${ }^{58}$ stated that $71.9 \%$ of mini-implants showed a controlled tipping or bodily movement, only $15.6 \%$ showed uncontrolled tipping, and $12.5 \%$ showed no movement. Additionally, results of studies differentiating the movement of mini-implants' parts have suggested that controlled tipping and bodily movement are the most common types of movement. Whereas maximum movement of the head mostly ranged between 1.0 and $2.0 \mathrm{~mm}$ in the force direction, the movement of the tail ranged up to $2.0 \mathrm{~mm}$ in the same direction and was no more than $-1.0 \mathrm{~mm}$ in the opposite direction.

Poggio et al.${ }^{64}$ recommended a distance of $1 \mathrm{~mm}$ between the miniimplant and the root surface, whereas Liou et al. ${ }^{30}$ advised $2 \mathrm{~mm}$ for safe clearance. Due to missing evidence and the lack of data from welldesigned clinical studies, no quantitative recommendations regarding safe distances have been offered. However, there is consensus regarding the appearance of clinically significant secondary replacement. The current results regarding the type of movement suggest it might be favourable not to insert implants in the middle of the inter-radicular space but instead to insert them slightly nearer to the root, away from the force direction. Insertion sites with good bone quality and thin mucosa should be preferred. If possible, insertion close to anatomical structures, such as dental roots, should be avoided, both to prevent any damage and to reduce the risk of implant loosening. Alves et al. ${ }^{63}$ recommended monitoring implant position during treatment to prevent contact with anatomical structures. El-Beialy et al. proposed that patients should be informed before insertion that the mini-implants' position might need to be redirected because of displacement. The aim of planning should be to provide a maximum range of action for the mini-implant, especially when long loading periods are necessary. ${ }^{62}$

\section{CONCLUSION}

The authors have affirmed that mini-implants provide good anchorage quality regarding orthodontic treatment. Primary displacement did not appear to be clinically relevant. Most of the studies confirmed that significant secondary displacement occurred under orthodontic loading over time. The level of displacement was clinically relevant, considering possible interference with anatomical structures, such as dental roots. Based on the given data concerning the amount and type of displacement, decentralized insertion within the inter-radicular space, away from force direction, might be favourable. Following this advice might help to minimize the risk of damaging anatomical structures and to reduce the failure rates of mini-implants. No quantitative recommendations have been given to date due to a lack of evidence. Further research regarding the amount of and factors affecting secondary displacement should be performed for better prediction of the space required needed in individual situations.

1 Fortini A, Lupoli M, Giuntoli F et al. Dentoskeletal effects induced by rapid molar distalization with the first class appliance. Am J Orthod Dentofacial Orthop 2004; 125(6): 697-704; discussion 704-705.

2 Kokich VG, Mathews DP. Surgical and orthodontic management of impacted teeth. Dent Clin North Am 1993; 37(2): 181-204.

3 Kircelli BH, Pektas ZO, Uckan S. Orthopedic protraction with skeletal anchorage in a patient with maxillary hypoplasia and hypodontia. Angle Orthod 2006; 76(1): 156163. 
4 Henry PJ. Clinical experiences with dental implants. Adv Dent Res 1999; 13: 147152.

5 Cornelis MA, de Clerck HJ. Maxillary molar distalization with miniplates assessed on digital models: a prospective clinical trial. Am J Orthod Dentofacial Orthop 2007; 132(3): 373-377.

6 Sugawara J, Kanzaki R, Takahashi I et al. Distal movement of maxillary molars in nongrowing patients with the skeletal anchorage system. Am J Orthod Dentofacial Orthop 2006; 129(6): 723-733.

7 Costa A, Raffainl M, Melsen B. Miniscrews as orthodontic anchorage: a preliminary report. Int J Adult Orthodon Orthognath Surg 1998; 13(3): 201-209.

8 Melsen B, Costa A. Immediate loading of implants used for orthodontic anchorage. Clin Orthod Res 2000; 3(1): 23-28.

9 Kanomi R. Mini-implant for orthodontic anchorage. J Clin Orthod 1997; 31(11): 763767.

10 Yao CC, Lai EH, Chang JZ et al. Comparison of treatment outcomes between skeletal anchorage and extraoral anchorage in adults with maxillary dentoalveolar protrusion. Am J Orthod Dentofacial Orthop 2008; 134(5): 615-624.

11 Upadhyay M, Yadav S, Patil S. Mini-implant anchorage for en-masse retraction of maxillary anterior teeth: a clinical cephalometric study. Am J Orthod Dentofacial Orthop 2008; 134(6): 803-810.

12 Wilmes B, Drescher D. Vertical periodontal ligament distraction - a new method for aligning ankylosed and displaced canines. J Orofac Orthop 2009; 70(3): 213-223.

13 Wilmes B, Nienkemper M, Drescher D. Application and effectiveness of a miniimplant- and tooth-borne rapid palatal expansion device: the hybrid hyrax. World $\mathrm{J}$ Orthod 2010; 11(4): 323-330.

14 Schatzle M, Mannchen R, Zwahlen M et al. Survival and failure rates of orthodontic temporary anchorage devices: a systematic review. Clin Oral Implants Res 2009; 20(12): 1351-1359.

15 Crismani AG, Bertl MH, Celar AG et al. Miniscrews in orthodontic treatment: review and analysis of published clinical trials. Am J Orthod Dentofacial Orthop 2010; 137(1): 108-113.

16 Su YY. Primary stability of orthodontic mini-implants: analysis of biomechanical properties and clinical relevance. Doctoral thesis, Department of Orthodotnics, Heinrich-Heine-Universität, Düsseldorf, Germany, 2009.

17 Wilmes B, Drescher D. Impact of bone quality, implant type, and implantation site preparation on insertion torques of mini-implants used for orthodontic anchorage. Int $\mathrm{J}$ Oral Maxillofac Surg 2011; 40(7): 697-703.

18 Wilmes B, Drescher D. Impact of insertion depth and predrilling diameter on primary stability of orthodontic mini-implants. Angle Orthod 2009; 79(4): 609-614.

19 Kang S, Lee SJ, Ahn SJ et al. Bone thickness of the palate for orthodontic mini-implant anchorage in adults. Am J Orthod Dentofacial Orthop 2007; 131(4 Suppl): S74-S81.

$20 \mathrm{Kim} \mathrm{HJ}$, Yun HS, Park HD et al. Soft-tissue and cortical-bone thickness at orthodontic implant sites. Am J Orthod Dentofacial Orthop 2006; 130(2): 177-182.

21 Miyawaki S, Koyama I, Inoue M et al. Factors associated with the stability of titanium screws placed in the posterior region for orthodontic anchorage. Am J Orthod Dentofacial Orthop 2003; 124(4): 373-378.

22 Wiechmann D, Meyer U, Buchter A. Success rate of mini- and micro-implants used for orthodontic anchorage: a prospective clinical study. Clin Oral Implants Res 2007; 18(2): 263-267.

23 Chen $\mathrm{CH}$, Chang $\mathrm{CS}$, Hsieh $\mathrm{CH}$ et al. The use of microimplants in orthodontic anchorage. J Oral Maxillofac Surg 2006; 64(8): 1209-1213.

24 Wilmes $\mathrm{B}$, Rademacher $\mathrm{C}$, Olthoff $\mathrm{G}$ et al. Parameters affecting primary stability of orthodontic mini-implants. J Orofac Orthop 2006; 67(3): 162-174.

25 Wilmes B, Ottenstreuer S, Su YY et al. Impact of implant design on primary stability of orthodontic mini-implants. J Orofac Orthop 2008; 69(1): 42-50.

26 Chen J, Esterle M, Roberts WE. Mechanical response to functional loading around the threads of retromolar endosseous implants utilized for orthodontic anchorage: coordinated histomorphometric and finite element analysis. Int J Oral Maxillofac Implants 1999; 14(2): 282-289.

27 Saito S, Sugimoto N, Morohashi T et al. Endosseous titanium implants as anchors for mesiodistal tooth movement in the beagle dog. Am J Orthod Dentofacial Orthop 2000; 118(6): 601-607.

28 Labanauskaite B, Jankauskas G, Vasiliauskas A et al. Implants for orthodontic anchorage. Meta-analysis. Stomatologija 2005; 7(4): 128-132.

29 Garfinkle JS, Cunningham LL Jr, Beeman CS et al. Evaluation of orthodontic miniimplant anchorage in premolar extraction therapy in adolescents. Am J Orthod Dentofacial Orthop 2008; 133(5): 642-653.

30 Liou EJ, Pai BC, Lin JC. Do miniscrews remain stationary under orthodontic forces? Am J Orthod Dentofacial Orthop 2004; 126(1): 42-47.

31 Chen $\mathrm{YH}$, Chang HH, Chen YJ et al. Root contact during insertion of miniscrews for orthodontic anchorage increases the failure rate: an animal study. Clin Oral Implants Res 2008; 19(1): 99-106.

32 Kuroda S, Yamada K, Deguchi T et al. Root proximity is a major factor for screw failure in orthodontic anchorage. Am J Orthod Dentofacial Orthop 2007; 131(4 Suppl): S68S73.

33 Maino BG, Weiland F, Attanasi A et al. Root damage and repair after contact with miniscrews. J Clin Orthod 2007; 41(12): 762-766; quiz 750.

34 Lee YK, Kim JW, Baek SH et al. Root and bone response to the proximity of a miniimplant under orthodontic loading. Angle Orthod 2010; 80(3): 452-458.

35 Brettin BT, Grosland NM, Qian F et al. Bicortical vs monocortical orthodontic skeletal anchorage. Am J Orthod Dentofacial Orthop 2008; 134(5): 625-635.
36 Morarend C, Qian F, Marshall SD et al. Effect of screw diameter on orthodontic skeletal anchorage. Am J Orthod Dentofacial Orthop 2009; 136(2): 224-229.

37 Akyalcin S, Mclver HP, English JD et al. Effects of repeated sterilization cycles on primary stability of orthodontic mini-screws. Angle Orthod 2013; 83(4): 674-679.

38 Chatzigianni A, Keilig L, Duschner $\mathrm{H}$ et al. Comparative analysis of numerical and experimental data of orthodontic mini-implants. Eur J Orthod 2011; 33(5): 468-475.

39 Holst Al, Karl M, Karolczak M et al. Quantitative assessment of orthodontic miniimplant displacement: the effect of initial force application. Quintessence Int 2010; 41(1): 59-66.

40 Su YY, Wilmes B, Honscheid R et al. Comparison of self-tapping and self-drilling orthodontic mini-implants: an animal study of insertion torque and displacement under lateral loading. Int J Oral Maxillofac Implants 2009; 24(3): 404-411.

41 Hong C, Truong P, Song HN et al. Mechanical stability assessment of novel orthodontic mini-implant designs: Part 2. Angle Orthod 2011; 81(6): 1001-1009.

42 Hong $\mathrm{C}$, Lee $\mathrm{H}$, Webster $\mathrm{R}$ et al. Stability comparison between commercially available mini-implants and a novel design: Part 1. Angle Orthod 2011; 81(4): 692-699.

43 Pittman JW, Navalgund A, Byun SH et al. Primary migration of a mini-implant under a functional orthodontic loading. Clin Oral Investig 2013; [Epub ahead of print].

44 Jang $\mathrm{HJ}$, Kwon SY, Kim SH et al. Effects of washer on the stress distribution of miniimplant. Angle Orthod 2011; 82(1): 137-144.

45 Motoyoshi M, Yano S, Tsuruoka T et al. Biomechanical effect of abutment on stability of orthodontic mini-implant. A finite element analysis. Clin Oral Implants Res 2005; 16(4): 480-485.

46 Singh S, Mogra S, Shetty VS et al. Three-dimensional finite element analysis of strength, stability, and stress distribution in orthodontic anchorage: a conical, selfdrilling miniscrew implant system. Am J Orthod Dentofacial Orthop 2011; 141(3) 327-336.

47 Liu TC, Chang $\mathrm{CH}$, Wong TY et al. Finite element analysis of miniscrew implants used for orthodontic anchorage. Am J Orthod Dentofacial Orthop 2012; 141(4): 468-476.

48 Chang JZ, Chen YJ, Tung YY et al. Effects of thread depth, taper shape, and taper length on the mechanical properties of mini-implants. Am J Orthod Dentofacial Orthop 2012; 141(3): 279-288.

49 Lee J, Kim JY, Choi YJ et al. Effects of placement angle and direction of orthopedic force application on the stability of orthodontic miniscrews. Angle Orthod 2013; 83(4): 667-673.

50 Dahlberg G. Statistical Methods for Medical and Biological Students. New YorkIntersience Publications, 1940.

51 Lifshitz $A B$, Munoz M. Evaluation of the stability of self-drilling mini-implants for maxillary anchorage under immediate loading. World J Orthod 2010; 11(4): 352-356.

52 Hedayati Z, Hashemi SM, Zamiri B et al. Anchorage value of surgical titanium screws in orthodontic tooth movement. Int J Oral Maxillofac Surg 2007; 36(7): 588-592.

53 Calderon JH, Valencia RM, Casasa AA et al. Biomechanical anchorage evaluation of mini-implants treated with sandblasting and acid etching in orthodontics. Implant Dent 2011; 20(4): 273-279.

54 Kinzinger G, Gulden N, Yildizhan F et al. Anchorage efficacy of palatally-inserted miniscrews in molar distalization with a periodontally/miniscrew-anchored distal jet. J Orofac Orthop 2008; 69(2): 110-120.

55 Mortensen MG, Buschang PH, Oliver DR et al. Stability of immediately loaded 3-and 6-mm miniscrew implants in beagle dogs-a pilot study. Am J Orthod Dentofacial Orthop 2009; 136(2): 251-259.

56 Ohmae M, Saito S, Morohashi T et al. A clinical and histological evaluation of titanium mini-implants as anchors for orthodontic intrusion in the beagle dog. Am J Orthod Dentofacial Orthop 2001; 119(5): 489-497.

57 Chang CS, Lee TM, Chang $\mathrm{CH}$ et al. The effect of microrough surface treatment on miniscrews used as orthodontic anchors. Clin Oral Implants Res 2009; 20(10): $1178-1184$

58 Wang YC, Liou EJ. Comparison of the loading behavior of self-drilling and predrilled miniscrews throughout orthodontic loading. Am J Orthod Dentofacial Orthop 2008; 133(1): 38-43.

59 Liu H, Lv T, Wang NN et al. Drift characteristics of miniscrews and molars for anchorage under orthodontic force: 3-dimensional computed tomography registration evaluation. Am J Orthod Dentofacial Orthop 2011; 139(1): e83-e89.

60 Frost HM. A 2003 update of bone physiology and Wolff's Law for clinicians. Angle Orthod 2004; 74(1): 3-15.

61 Frost HM. Wolff's Law and bone's structural adaptations to mechanical usage: an overview for clinicians. Angle Orthod 1994; 64(3): 175-188.

62 El-Beialy AR, Abou-EI-Ezz AM, Attia KH et al. Loss of anchorage of miniscrews: a 3-dimensional assessment. Am J Orthod Dentofacial Orthop 2009; 136(5): 700-707.

63 Alves M Jr, Baratieri C, Nojima LI. Assessment of mini-implant displacement using cone beam computed tomography. Clin Oral Implants Res 2011; 22(10): 1151-1156.

64 Poggio PM, Incorvati C, Velo S et al. "Safe zones": a guide for miniscrew positioning in the maxillary and mandibular arch. Angle Orthod 2006; 76(2): 191-197. Attribution-NonCommercial-NoDerivative Works 3.0 Unported License. To view a copy of this license, visit http:// creativecommons.org/licenses/by-nc-nd/3.0 